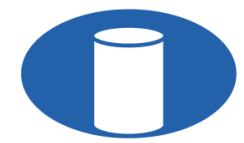

IBRACON Structures and Materials Journal

Revista IBRACON de Estruturas e Materiais

IBRACON

ISSN 1983-4195

ismj.org

ORIGINAL ARTICLE

\title{
Effect of Carbon Nanotubes (CNTs) aspect ratio on the rheology, thermal conductivity and mechanical performance of Portland cement paste
}

\author{
Efeito da relação de aspecto dos nanotubos de carbono (NTCS) na reologia, \\ condutividade térmica e desempenho mecânico de pastas de cimento Portland
}

\author{
Eduardo Batiston ${ }^{\mathrm{a}, \mathrm{b}}$ (D) \\ Philippe Jean Paul Gleize ${ }^{\mathrm{a}}(\mathbb{D}$ \\ Paula Mezzomo ${ }^{\mathrm{a}}$ (1) \\ Fernando Pelisser ${ }^{\mathrm{a}}$ (1) \\ Paulo Ricardo de Matos ${ }^{\text {a,c }}$ (D)
}

\begin{abstract}
${ }^{a}$ Universidade Federal de Santa Catarina - UFSC, Departamento de Engenharia Civil, Programa de Pós-graduação em Engenharia de Civil PPGEC, Florianópolis, SC, Brasil

bUniversidade Comunitária da Região de Chapecó - UNOCHAPECÓ, Departamento de Engenharia Civil, Chapecó, SC, Brasil

'Universidade Federal de Santa Maria - UFSM, Santa Maria, RS, Brasil
\end{abstract}

Received 13 October 2020

Accepted 01 December 2020

\begin{abstract}
Carbon nanotubes (CNTs) are potential candidates to enhance the heat balance of concrete, reducing internal stresses caused by differential heating in massive concrete elements. The higher the aspect ratio (AR) and content of CNTs, the greater the expected thermal conductivity (TC). However, high AR may impair the proper dispersion of CNTs in cementitious matrix, potentially harming the workability and mechanical strength of the composite. This work evaluated the effect of the AR $(35,250,900$, and 3500 ) and content $(0.05 \%$ and $0.10 \%)$ of CNTs on the TC, rheology (squeeze flow), and mechanical strength of cement paste. Results showed that $0.05 \%$ CNT increased the TC of paste by up to $15 \%$ for AR of 250 , but further increasing AR progressively reduced the TC of the composite. In turn, $0.10 \% \mathrm{CNT}$ incorporation did not result in significant TC gains. The yield stress and viscosity of the mixes progressively increased as CNTs content and AR increased, by up to $119 \%$ compared with plain cement paste. No significant differences were observed in 28-day compressive strength with $0.05 \% \mathrm{CNT}$ incorporation, while $0.10 \%$ CNT led to slight strength reductions for some mixes. Regarding flexural strength, $0.05 \%$ incorporation of either CNT decreased the strength of the mixes while $0.10 \%$ incorporation generally compensated this reduction, except for the lowest aspect ratio. Overall, CNTs with intermediate AR (around 250) was effective in improving the thermal conductivity of cement paste, increasing it by $15 \%$ with relatively low content $(0.05 \%)$ while did not significantly impair the fresh and mechanical performance of the composite.
\end{abstract}

Keywords: carbon nanotube, aspect ratio, Portland cement, rheology, thermal conductivity.

Resumo: Nanotubos de carbono (NTCs) são potenciais candidatos a melhorar o balanço térmico do concreto, reduzindo as tensões internas causadas pelo aquecimento diferencial em elementos maciços de concreto. Quanto maior a relação de aspecto (RA) e o teor de NTCs, maior será a condutividade térmica (CT) esperada. Porém, uma RA elevada pode prejudicar a dispersão adequada do NTCs na matriz cimentícia, potencialmente prejudicando a trabalhabilidade e resistência mecânica do compósito. Este estudo avaliou o efeito do RA (35, $250,900$ e 3500$)$ e teor $(0,05 \%$ e $0,10 \%)$ de NTCs na CT, reologia (squeeze flow) e resistência mecânica das pastas de cimento. Os resultados mostraram que a incorporação de $0,05 \%$ NTC aumentou a CT da pasta em até $15 \%$ para uma RA de 250 , mas o aumento da RA reduziu progressivamente a CT do compósito. Por sua vez, a incorporação de $0,10 \%$ NTC não resultou em ganhos significativos de CT. A tensão de escoamento e a viscosidade das misturas aumentaram progressivamente com o aumento do teor de NTC e da RA, em até

Corresponding author: Paulo Ricardo de Matos. E-mail: paulorm.matos@gmail.com;paulo.matos@ufsm.br

Financial support: None.

Conflict of interest: Nothing to declare.

This is an Open Access article distributed under the terms of the Creative Commons Attribution License, which permits unrestricted use, distribution, and reproduction in any medium, provided the original work is properly cited. 
$119 \%$ em comparação com a pasta de cimento sem NTCs. Nenhuma diferença significativa foi observada na resistência à compressão de 28 dias com incorporação de $0,05 \%$ NTCs, enquanto $0,10 \%$ NTCs levou a pequenas reduções de resistência para algumas misturas. Em relação à resistência à flexão, a incorporação de $0,05 \%$ de qualquer um dos NTCs diminuiu a resistência das misturas, enquanto a incorporação de $0,10 \%$ geralmente compensou essa redução, exceto pela RA mais baixa. No geral, os NTCs com RA intermediária $(\sim 250)$ foram eficazes em melhorar a condutividade térmica da pasta de cimento, aumentando-a em 15\% com teor relativamente baixo $(0,05 \%)$, enquanto não prejudicou significativamente o desempenho fresco e mecânico do compósito.

Palavras-chave: nanotubos de carbono, relação de aspecto, cimento Portland, reologia, condutividade térmica.

How to cite: E. Batiston, P. J. P. Gleize, P. Mezzomo, F. Pelisser, and P. R. de Matos, "Effect of Carbon Nanotubes (CNTs) aspect ratio on the rheology, thermal conductivity and mechanical performance of Portland cement paste", Rev. IBRACON Estrut. Mater., vol. 14, no. 5, e14510, 2021, https://doi.org/10.1590/S1983-41952021000500010

\section{INTRODUCTION}

Recently, nanotechnology has gained much attention for research in the development of materials with unique properties. Nanoengineering (or nanomodification) of Portland cement-based materials is a rapid emerging field. Synthesis and assembly of materials with dimensions in the range $0.1-100 \mathrm{~nm}$ offer possibilities for the development of materials with new functions and smart properties not currently available [1]. Concrete can be nanoengineered by incorporating nanosized additions to control material behavior and add novel properties, or by grafting molecules onto cement particles, cement phases, aggregates, and admixtures that can provide surface functionality to promote specific interfacial interactions [2], [3]. Furthermore, recent studies reported the synthesis of nanoparticles directly on Portland clinker [4].

Carbon nanotubes (CNTs) are potential candidates for use as nano reinforcements in Portland cement-based materials [5]. It exhibits extraordinary strength (tensile strength in the range of GPa) and modulus of elasticity in the order of TPa, in addition to having unique electronic and chemical properties [1]. As a result, several works showed that CNTs improved the compressive strength [6]-[10], tensile/flexural strength [7], [11]-[14], and modulus of elasticity [8], [15] of cementitious composite. In addition, CNTs may improve the durability of composite mainly by reducing the porosity of the cementitious matrix [10], [16]-[18].

Most research efforts have focused on the influence of CNTs on the mechanical performance and durability of cementitious composites, but very few studies investigated its effect on thermal properties. In fact, to the authors' best knowledge, there are no studies investigating the effect of CNTs aspect ratio on the thermal conductivity of cementitious composite. Due to the high thermal conductivity of CNTs (about $750 \mathrm{~W} / \mathrm{m} \cdot \mathrm{K}[19]$ ), they have been used to enhance the thermal conductivity of heating or cooling fluids [20]. In addition, its aspect ratio ranges from 20 up to 10000, making CNTs an interesting choice for electrical/thermal conductive or percolating networks at lower loadings. Although low thermal conductivity values are often desired for building materials (e.g. to improve thermal insulation), high thermal conductivity can be used as a tool to improve the heat balance of large volumes of concrete [21], facilitating the cooling of the interior of massive concrete elements (e.g. dams and foundation elements) and avoiding the appearance of internal stresses caused by differential heating [22]. There are reports of substantial increases in the thermal conductivity with CNTs incorporation in epoxy [23]-[25] and polyurethane composites [26]. Thus, the incorporation of CNTs in Portland cement matrix may increase the thermal conductivity of the composite.

Regarding the fresh state performance of CNT-reinforced cementitious composites, the incorporation of nanotubes tends to negatively affect the flowability of the materials. Overall, the very high specific surface area of CNTs and their trend for clustering tend to reduce the flowability of cement paste when CNTs are added [27]. However, such flowability loss may be overcome with the incorporation of superplasticizer as confirmed by Skripkiunas et al. [28]. In this context, most of the studies investigated the effect of CNTs dispersion mechanism and content on the fresh state performance of cement paste, while the effect of the CNTs aspect ratio was few investigated. Collins et al. [29] investigated such effect through the mini slump test, but this is an empirical test and can lead to errors in estimating the rheological properties of the material.

Thus, this work investigated the effect of CNTs aspect ratio on the thermal conductivity and rheological properties of cement paste (through the squeeze flow test), in addition to mechanical performance characterization. 


\section{EXPERIMENTAL PROGRAM}

\subsection{Materials and mixes}

Multiwalled CNTs with four different aspect ratios (i.e. length/diameter ratios) were used: 35, 250, 900, and 3500. The CNTs were purchased from Nanostructured \& Amorphous Materials and Cheap Tubes Inc. The characteristics of the CNTs used were provided by the manufacturers and are shown in Table 1. One can note that CNT's specific surface area (SSA) generally increased as its aspect ratio increased, in agreement with previous literature reports [30], [31].

Table 1. Carbon nanotubes characteristics.

\begin{tabular}{ccccccc}
\hline Type & Density $\left(\mathbf{g} / \mathbf{c m}^{\mathbf{3}}\right)$ & $\begin{array}{c}\text { External } \varnothing \\
(\mathbf{n m})\end{array}$ & $\begin{array}{c}\text { Length } \\
(\boldsymbol{\mu m})\end{array}$ & Aspect ratio & Purity $(\mathbf{\%})$ & SSA $\left(\mathbf{m}^{2} / \mathbf{g}\right)$ \\
\hline CNT-35 & $1.7-1.9$ & $40-60$ & $0.5-2$ & $17-50$ & 95 & $>40$ \\
CNT-250 & 2.1 & $40-70$ & $5-15$ & $125-375$ & 94 & $>40$ \\
CNT-900 & $1.5-1.9$ & $20-30$ & $10-30$ & $333-1500$ & 95 & 110 \\
CNT-3500 & $1.5-1.9$ & $8-15$ & $10-50$ & $666-6250$ & 95 & 233 \\
\hline
\end{tabular}

An ordinary Portland cement (CP I-S 32 [32]), a polycarboxylate-based superplasticizer (with density of $1.09 \mathrm{~g} / \mathrm{cm}^{3}$ and solid content of $30.5 \%)$ and distilled water were used for paste production. The water/cement $(\mathrm{w} / \mathrm{c})$ ratio and the superplasticizer content were fixed for all the mixes, respectively at 0.30 and $0.1 \%$ by weight of cement. The use of such w/c ratio was previously reported in the literature [27], [28], [30], while this superplasticizer content allowed to produce flowable pastes. Each CNT was added in the amount of $0.05 \%$ (CNT 0.05) and $0.10 \%$ (CNT 0.10) by weight of cement. Cement paste without CNT (Ref) was also prepared for comparison purpose.

\subsection{Sample preparation}

Firstly, CNTs, water and superplasticizer were mixed and sonicated for $20 \mathrm{~min}$ at $55 \mathrm{kHz}$ in a low energy water bath sonicator (to prevent damaging the CNTs). Then, this suspension was added to the mixer container together with cement, and the paste was mixed for $3 \mathrm{~min}$. After mixing, a portion of the sample was immediately used for the rheological measurements, while the remainder was used for casting the specimens as seen next.

For each mix, the following specimens were cast: 3 cylindrical specimens of $20 \mathrm{~mm}$ x $50 \mathrm{~mm}$ (diameter x height) for thermal conductivity measurements; 5 cylindrical specimens of $20 \mathrm{~mm}$ x $40 \mathrm{~mm}$ (diameter $\mathrm{x}$ height) for compressive strength tests; and 4 prismatic specimens of $5 \mathrm{~mm}$ x $20 \mathrm{~mm}$ x $60 \mathrm{~mm}$ (thickness $\mathrm{x}$ height $\mathrm{x}$ length) for flexural strength tests. One day after casting, the specimens were demolded and stored in lime-saturated water until testing. All the tests were conducted at 28 days of age.

\subsection{Testing methods}

The rheological behavior of the pastes was evaluated through the squeeze flow test. It consists of applying a load on a fresh disc sample placed between two parallel plates at a constant normal strain [33], [34]. This test was successfully used to evaluate the fresh state behavior of cement pastes [35], [36] and mortars [37]-[39]. Tests were conducted in paste samples of $93 \mathrm{~mm}$ in diameter and $10 \mathrm{~mm}$ in thickness, using a universal testing machine Instron 5569. The displacement rate was $0.1 \mathrm{~mm} / \mathrm{s}$ and the total displacement was $5 \mathrm{~mm}$. A $25 \mathrm{~mm}$-diameter steel punch was used, meeting the minimum Øsample/Øpunch ratio of 3 prescribed by Min et al. [35] to minimize compressive stresses generated by sample confinement. Tests were conducted on three fresh samples for each mix.

The rheological parameters viscosity ( $\eta$, in Pa.s) and yield stress ( $\tau 0$, in Pa) were estimated using respectively Equations 1 and 2, proposed by Meeten [34]. Although the actual yield stress is measured by rotational rheometry [40], similar approaches have been successfully used to estimate the yield stress of cement-based materials [37], [38], [41].

$\eta=\frac{64 F t}{3 \pi\left(h^{-2}-h_{0}^{-2}\right) D^{4}}$ 
$\tau_{0}=\frac{12 h F}{\pi D^{3}}$

where $F=$ force $(\mathrm{N}) ; t=$ testing time elapsed (s); $h_{0}=$ initial sample height $(\mathrm{mm}) ; h=$ final sample height $(\mathrm{mm})$; and $D=$ sample diameter $(\mathrm{mm})$.

At 28 days, compressive and flexural strength (three-point bending) tests were conducted using the same universal testing machine mentioned above, with testing rates of 2.5 and $0.01 \mathrm{~mm} / \mathrm{min}$, respectively. Prior to flexural strength test, the density of the specimens was determined using a hydrostatic balance. Thermal conductivity tests were conducted using a C-Therm TCi analyzer, based on the transient plane source (TPS) method [42]. A Wakefield thermal grease was used as a contact agent between the probe and the sample.

\section{RESULTS AND DISCUSSIONS}

\subsection{Rheological behavior}

Figure 1 shows the squeeze flow curves of the pastes and Figure 2 shows the rheological parameters of the mixes. The increase in CNT content progressively increased the yield stress and viscosity of paste for a given aspect ratio. These increases were of up to $119 \%$ both for yield stress and viscosity (CNT $3500-0.10 \%$ ), in comparison with the Ref mix. This may be associated with the very high specific surface area of CNTs (40-223 $\mathrm{m}^{3} / \mathrm{g}$, shown in Table 1) and their tendency to agglomerate. According to Roussel et al. [43], in cementitious suspension, the colloidal surface interactions form a particle network within the first few seconds. In addition, the first hydration products form C-S-H bridges between the particles already in the first 100 seconds. Both phenomena increase the hardness of the particle network - and therefore of the cement paste - in a very early age. In this regard, the increase in flocculation strength and floc size with the incorporation of nanomaterials was already reported for cementitious systems [3], [44], which can increase the stiffness of paste, consequently increasing its yield stress and viscosity. In addition, CNTs tend to selfassociate into micro-scale agglomerates [45]. Such clustering traps part of the water and superplasticizer, reducing their availability for lubricating and dispersing the cement grains and the nanotubes itself [10]. These results are in line with those reported in the literature. Skripkiunas et al. [27] found yield stress increases of up to $270 \%$ when incorporated $0.12 \%$ CNT in cement pastes with superplasticizer. Ma et al. [46] observed viscosity and yield stress increases of about $30 \%$ when incorporated $0.01 \%$ CNT in Portland cement paste. Mohamadian et al. [47] observed viscosity and yield stress increases of up to $16 \%$ and $61 \%$, respectively, when incorporated up to $5 \%$ of a Methyl Methacrylate-CNT composite in oil/gas wellbore cement paste. Despite yield stress increases, Skripkiunas et al. [27] reported reductions in the shear thickening behavior with CNTs incorporation. This phenomenon corresponds to the progressive increase in viscosity as the shear rate increases. In cementitious systems, it is mainly caused by the formation of clusters of unadsorbed superplasticizer molecules, which hinders the flow during shear [48], [49]. Considering that superplasticizer is commonly used to disperse CNTs in cementitious matrix [10], [29], [50], the incorporation of CNTs may adsorb such "leftover" polymer molecules, reducing the shear thickening occurrence. This may be of practical interest, such as for pumping applications where the material is subjected to high shear rates.

Furthermore, for a given CNT content, the increase in its aspect ratio generally increased the yield stress and viscosity of paste, and these increases were higher for the highest CNT content. For example, CNT-3500 had yield stress and viscosity $56 \%$ higher than CNT-35 for $0.05 \%$ CNT, and $85 \%$ higher for $0.10 \%$ CNT. This can be explained by the higher difficulty to disperse longer CNTs, together with the increase in the SSA of CNT as its aspect ratio increased (Table 1). In agreement with that, Abu Al-Rub et al. [51] investigated the effect of CNTs aspect ratio on the mechanical properties of cement paste, finding that shorter CNTs resulted in higher dispersion in cement paste and improved homogeneity (i.e. reduced CNT-free volume of cement paste). Also, electron microscopy images indicated that longer CNTs further bridge the neighboring hydration products, which can increase the stiffness of the paste as discussed above. Similarly, Konsta-Gdoutos et al. [15] concluded that longer CNTs are more difficult to disperse. Regarding the impact of CNT aspect ratio on the fresh performance of cement paste, Collins et al. [29] incorporated CNTs with average aspect ratios of 200, 1000 and 1125 in cement pastes with $0.05 \%$ CNT, finding no significant differences in the mini slump flow (from 67.6 to $69.4 \mathrm{~mm}$ ) for the mixes. However, two aspects must be stressed in their study: (i) the authors did not incorporate superplasticizer in these pastes, which may prevent proper dispersion of CNTs; and (ii) previous studies [52] showed that the mini slump test may be inaccurate to predict the yield stress of paste especially at such low mini slump spread, i.e., around $60 \mathrm{~mm}$ where the sample is not completely self-leveling. 
In turn, the squeeze flow test has been shown to be a precise tool to evaluate the rheological properties of cement-based composites [37], [41] and is more sensitive to small property variations.
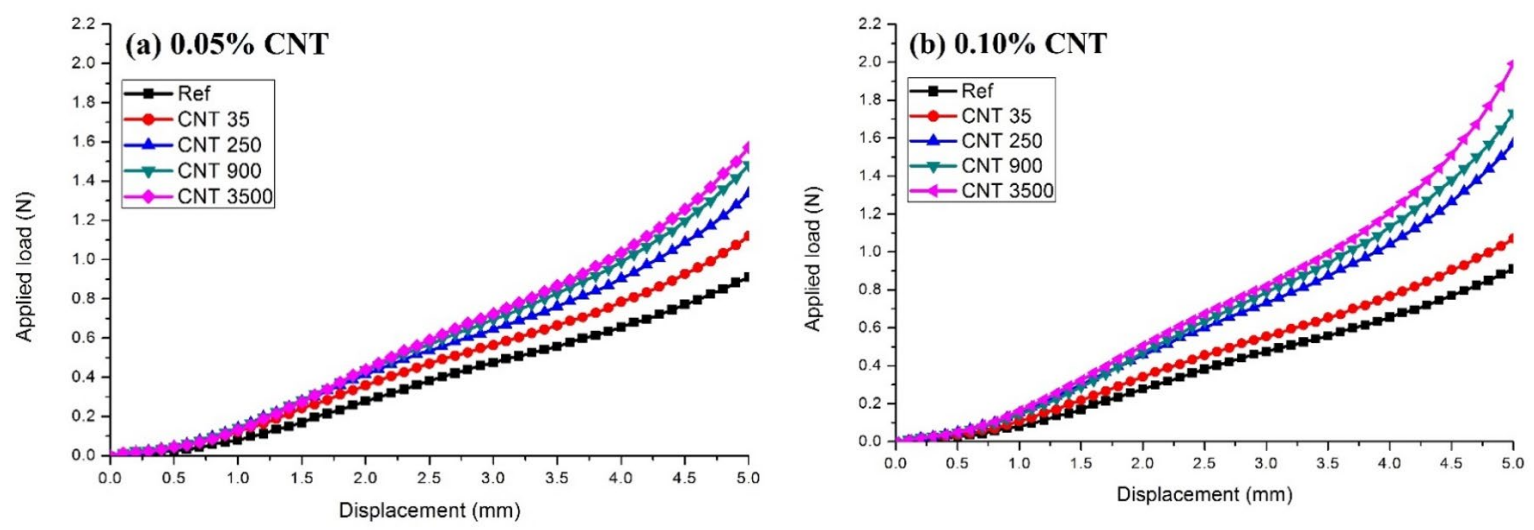

Figure 1. Squeeze flow test curves (applied load vs. displacement) of the pastes. (a) $0.05 \%$ CNT; (b) $0.10 \%$ CNT.
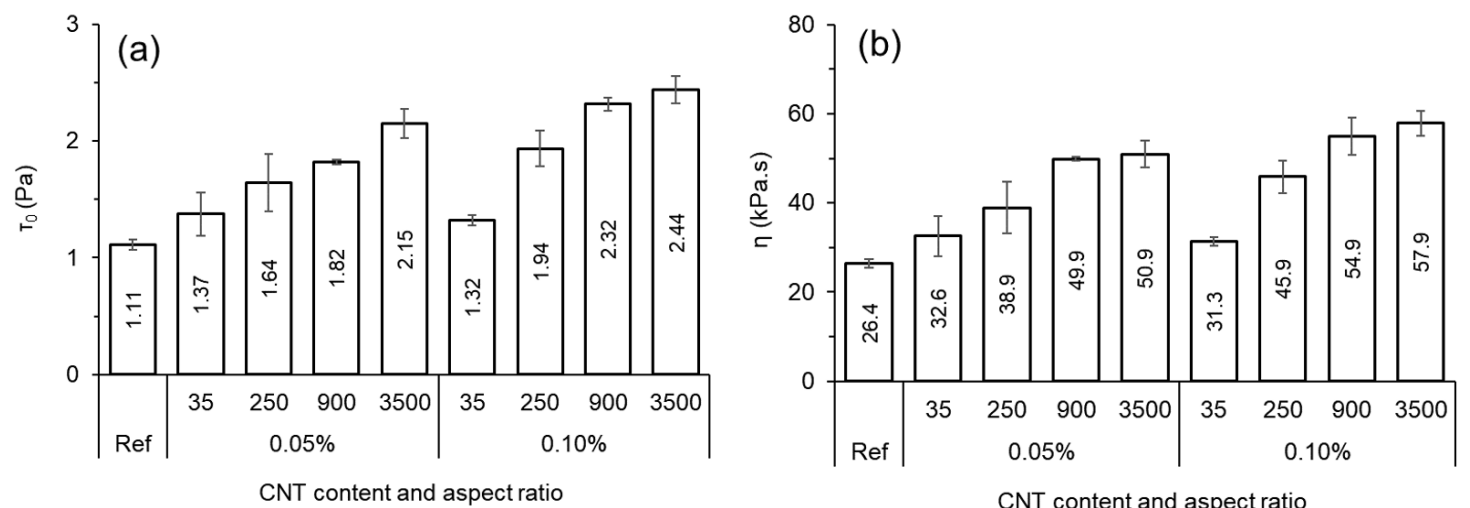

Figure 2. Rheological parameters of the pastes. (a) yield stress; (b) viscosity.

\subsection{Mechanical tests}

Figure 3 and Figure 4 respectively show the compressive and flexural strength of the pastes at 28 days. No significant differences were observed between the compressive strength of the reference mix and the paste with $0.05 \%$ CNT, regardless of the CNTs aspect ratios. However, a slight compressive strength decrease was observed in mixtures with $0.10 \%$ CNT. The lack of significant strength gain (or even strength reduction) with CNTs incorporation was already addressed in the literature. MacLeod et al. [53] conducted an extensive survey on the effect of CNTs incorporation on the 28-day compressive strength of cement-based composites. From 13 mixes with water/binder ratio below 0.35 (as used in the current work), only two mixes had a significant compressive strength increase with nanotube incorporation. Ma et al. [46] found equivalent 7- and 28-day compressive strength for plain and CNT-reinforced fly ash-blast furnace slag-cement mortars with $0.01 \%$ CNT. Collins et al. [29] also found 28-day compressive strength reductions of $8 \%$ and $11 \%$ when incorporated $0.05 \%$ CNT with mean aspect ratios of 200 and 1125, respectively, compared with plain cement paste. Finally, Hu et al. [6] and Mohsen et al. [54] reported negligible differences in compressive strength with CNTs addition in up to $0.10 \%$. By contrast, in the survey of MacLeod et al. [53], the highest 28 -day strength improvements were reported for mixes with water/binder ratios above 0.45 , reaching improvements of the order of $60 \%$. This trend can be associated with the harder dispersion of CNTs in paste with low water/binder ratio, also reported by Mendoza-Reales et al. [55] and Zhou et al. [9].

Regarding the flexural strength, incorporating $0.05 \%$ CNT decreased the strength of composite regardless of the CNTs aspect ratio. This was confirmed by one-way ANOVA, dividing the samples in groups according to the CNT type used; 
p-values were $0.096,0.456,0.245$ and 0.084 respectively for CNT 35, 250, 900 and 3500, indicating significant difference for $95 \%$ reliability. Similarly, Tyson et al. [56] reported flexural strength reduction of about $70 \%$ with CNTs incorporation at the latter age tested (i.e. 21 days). Flexural strength is generally more sensitive to heterogeneities and defects in the matrix than compressive strength [57]. In turn, increasing the CNT content up to $0.10 \%$ generally compensated the strength loss observed for $0.05 \%$ CNT incorporation, except for CNT-35. This behavior was similar to the one reported by Mohsen et al. [54], which obtained equivalent strengths for $0 \%$ and $0.08 \%$ CNT incorporation. According to Sobolkina et al. [58], during load, cracks are originated in the weaker zones of the composite which generally correspond to the contacts between the C-S-H regions. CNTs bridge C-S-H regions (in the scale of around $1 \mu \mathrm{m}$ ) and promotes an interlock of needle-like C-S-H crystals, therefore reinforcing such week zones and promoting strength increase. In the case of CNT-35, its low length (around $1 \mu \mathrm{m}$ compared with 5-50 $\mu \mathrm{m}$ for the others) prevented the flexural strength gain promoted by increased nanotube content. These results agree with the findings of Abu Al-Rub et al. [51], which evaluated cement pastes with "long CNTs" (length of 10-30 $\mu \mathrm{m}$, comparable with CNT-3500) and "short CNTs" (length of $1.5 \mu \mathrm{m}$, comparable with CNT-35) in $0.04 \%$ and $0.1 \%$. The authors observed that long CNTs led to 28 -day flexural strengths from $20 \%$ to $30 \%$ higher than short CNTs did, for the same incorporation level.

Concerning the effect of CNTs aspect ratio, the main conclusion of Konsta-Gdoutos et al. [15], [30] and Abu AlRub et al. [51] was that, to achieve the same mechanical performance level, lower CNTs content are needed as the aspect ratio increases. In our work, the optimum CNT content and aspect ratio were $0.10 \%$ and 900 , respectively; higher aspect ratio decreased the compressive strength while shorter aspect ratio prevented proper flexural strength improvement.

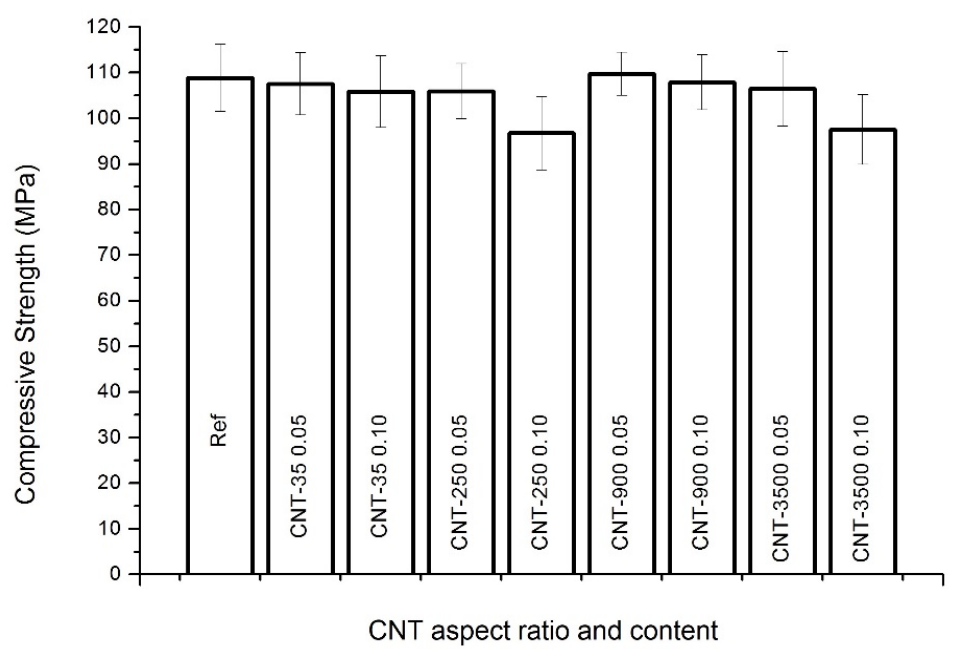

Figure 3. Compressive strength of the pastes at 28 days.

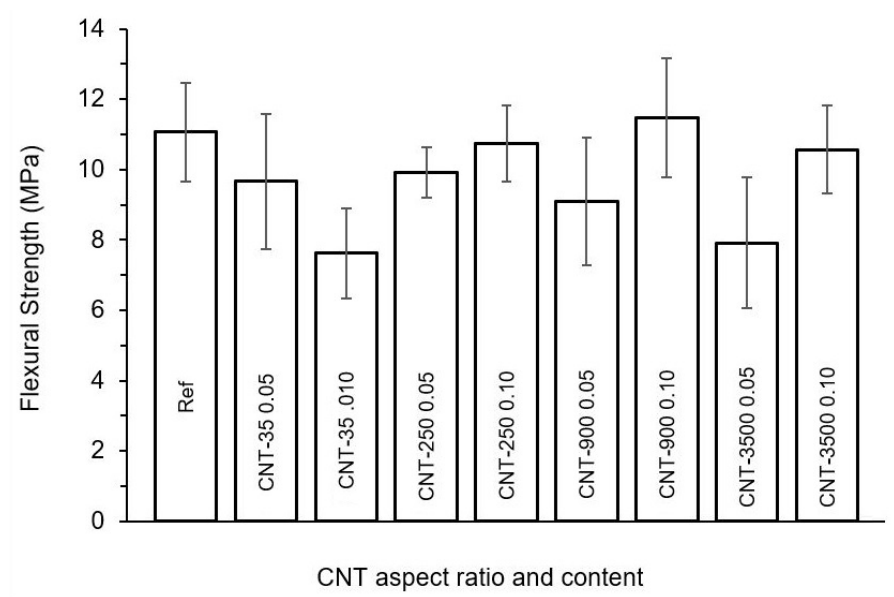

Figure 4. Flexural strength of the pastes at 28 days. 


\subsection{Thermal conductivity}

Figure 5 shows the density of the pastes and Figure 6 shows the effect of the CNTs on their thermal conductivity. No significant differences were observed between the density of the composites; therefore, the differences in thermal conductivity may be attributed to the presence of CNTs. The addition of $0.05 \% \mathrm{CNT}$ improved the thermal conductivity of the composite by up to $15 \%$ when the CNTs aspect ratio increased up to 250 , regardless of the CNT content. This finding was expected, since CNTs thermal conductivity is about 1000 times higher the one of plain cement paste (discussed next), and increasing the CNTs aspect ratio tends to increase the conductivity of the composite since it enables the formation of a more extensive network of nanotubes at the same weight content [23]. Furthermore, incorporating $0.05 \%$ of both CNT-900 and CNT-3500 slightly decreased the thermal conductivity of composite compare with the $0.05 \%$ CNT-250 mix, but they were still higher those of the $0.05 \%$ CNT-35 and Ref mixes. A similar overall trend was observed for $0.10 \%$ CNT incorporation when its aspect ratio increased (except for CNT-3500), but the thermal conductivity values found for the highest CNT content were lower than those found for the lowest CNT content when comparing respective aspect ratios. From the viewpoint of thermal conductivity, this behavior seems to be contradictory. However, increasing the CNT content and aspect ratio tend to increase the difficulty to homogeneously disperse it on the cementitious matrix, and this was evidenced by the fact that the highest CNTs aspect ratio and content led to the lowest thermal conductivity among the pastes, even lower than that of plain cement paste. Nonetheless, thermal conductivity tests showed a substantial improvement on such property (by up to $15 \%$ ) with the incorporation of relatively low content of CNTs $(0.05 \%)$, confirming the potential of this nanomaterial to improve the thermal conductivity of cement-based materials.

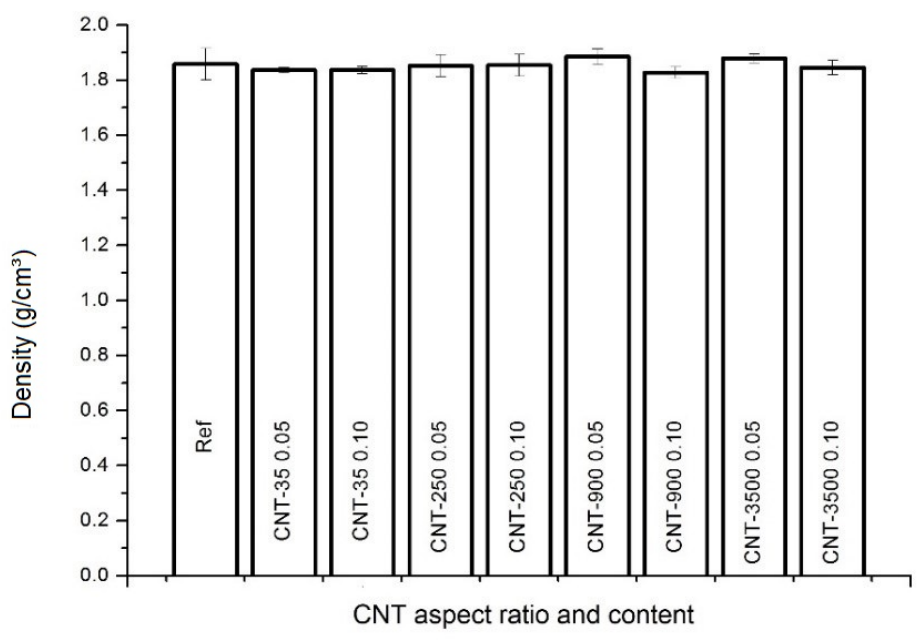

Figure 5. Density of the cement pastes.

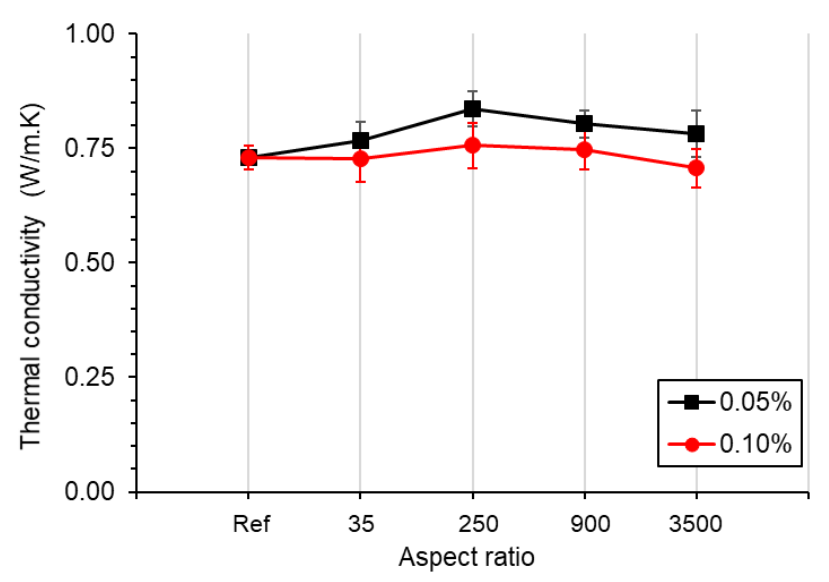

Figure 6. Thermal conductivity of the pastes as a function of CNT aspect ratio and content. 
Furthermore, the experimental values of thermal conductivity were compared with theoretical values calculated using the Lewis-Nielsen model. The advantages of this model are its simplicity and coverage of a broad range of particle shapes and patterns, particularly the fiber aspect ratio [59], [60]. The thermal conductivity $(K)$ of a two-phase system composed of a non-conductive matrix (here, cementitious matrix) and a conductive filler (here, CNT) was determined by Equations 3-5, according to works reported in the literature [59], [61].

$K=k_{1}\left(\left(1+A B \Psi \varnothing_{2}\right)\right)$

$B=\left(\frac{k_{2}}{k_{1}}-1\right) /\left(\frac{k_{2}}{k_{1}}+A\right)$

$\Psi=1+\left(\frac{1-\phi_{m}}{\phi_{m^{2}}}\right) \phi_{2}$

Where $k_{1}=$ thermal conductivities of the cement paste matrix $(\mathrm{W} / \mathrm{m} \cdot \mathrm{K}) ; k_{2}=$ thermal conductivities of CNT (equal to 750 , estimated from [19]) $(\mathrm{W} / \mathrm{m} \cdot \mathrm{K}) ; A=\mathrm{CNT}$ aspect ratio; $\varnothing_{2}=$ filler volume fraction; and $\phi_{m}=$ maximum filler volume fraction.

Figure 7 compares the measured thermal conductivity values with those predicted by the Lewis-Nielsen model and Table 2 details the values. Good agreement between the theoretical and measured values was observed for the incorporation of CNT-35 and CNT-250 in $0.05 \%$ (differences of up to $2.7 \%$ ). However, as the CNTs aspect ratio and content increased, the experimental results deviated from those predicted by the Lewis-Nielsen model. This is because the theoretical model assumes that the "filler" phase (i.e. CNTs) is perfectly distributed throughout the matrix, while such homogeneity worsens as the CNT content and aspect ratio increases. Finally, Figure 7 shows the great potential of CNTs to improve the thermal conductivity of cement composite, more than doubling the conductivity of the paste with the incorporation of $0.10 \%$ CNT in theory.

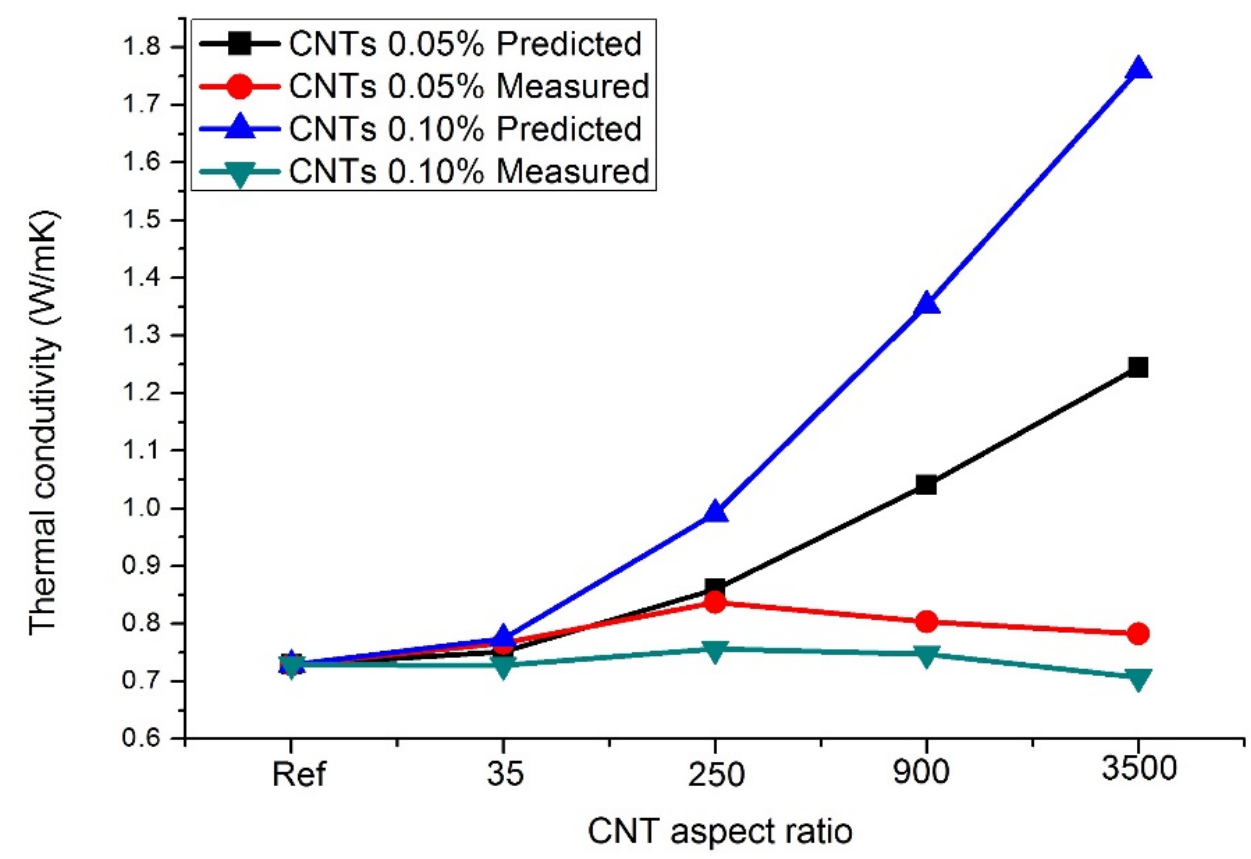

Figure 7. Predicted (Lewis-Nielsen model) and measured thermal conductivity of the CNT-reinforced cement pastes, for the different CNT aspect ratio and content. 
Table 2. Detailed data from the Lewis-Nielsen prediction model.

\begin{tabular}{lcccccc}
\hline & CNT volume fraction & A & B & $\boldsymbol{\Psi}$ & PTC $(\mathbf{W} / \mathbf{m} \cdot \mathbf{K})$ & $\mathbf{M T C}(\mathbf{W} / \mathbf{m} \cdot \mathbf{K})^{*}$ \\
\hline Reference paste & 0 & - & - & - & 0.729 & $0.729(0.026)$ \\
CNT-35-0.05\% & 0.00089 & 35 & 0.9661 & $\sim 1$ & 0.752 & $0.766(0.042)$ \\
CNT-35-0.1\% & 0.00178 & 35 & 0.9661 & $\sim 1$ & 0.774 & $0.728(0.051)$ \\
CNT-250-0.05\% & 0.00089 & 250 & 0.8037 & $\sim 1$ & 0.860 & $0.837(0.038)$ \\
CNT-250-0.1\% & 0.00178 & 250 & 0.8037 & $\sim 1$ & 0.991 & $0.756(0.049)$ \\
CNT-900-0.05\% & 0.00089 & 900 & 0.5328 & $\sim 1$ & 1.041 & $0.803(0.029)$ \\
CNT-900-0.1\% & 0.00178 & 900 & 0.5328 & $\sim 1$ & 1.352 & $0.747(0.042)$ \\
CNT-3500-0.05\% & 0.00089 & 3500 & 0.2269 & $\sim 1$ & 1.245 & $0.782(0.051)$ \\
CNT-3500-0.1\% & 0.00178 & 3500 & 0.2269 & $\sim 1$ & 1.760 & $0.707(0.042)$ \\
\hline
\end{tabular}

PTC: Predicted thermal conductivity; MDC: Measured thermal conductivity; *average (standard deviation).

\section{CONCLUSIONS}

This work investigated the effect of the CNTs aspect ratio on the rheology, thermal conductivity and mechanical properties of Portland cement paste. Specifically, CNTs with aspect ratios of 35, 250, 900, and 3500 were added in $0.05 \%$ and $0.10 \%$ over the cement weight. Based on the results presented, the following conclusions were drawn:

(i) Squeeze flow test showed that the increase in CNT content progressively increased the yield stress and viscosity of the paste, by up to $119 \%$ in comparison with plain cement paste. The increase in CNTs aspect ratio also increased these properties for a given incorporation level, reaching values $86 \%$ higher when $0.10 \%$ CNT-3500 was incorporated compared with the same level of CNT-35.

(ii) No significant differences were observed in the compressive strength of paste when $0.05 \%$ CNT was incorporated regardless of its aspect ratio. In turn, $0.10 \%$ incorporation led to slight strength reductions in some mixes (i.e. for CNT-250 and -3500). Regarding flexural strength, $0.05 \%$ incorporation of either CNTs decreased the strength of the mixes, while $0.10 \%$ incorporation generally compensated this reduction except for the lowest aspect ratio.

(iii) Thermal conductivity tests showed that incorporating $0.05 \%$ CNT improved the thermal conductivity of the composite regardless of the CNTs aspect ratio. These improvements were of up to $15 \%$ for CNT-250. In turn, further incorporating CNTs did not result in major improvements in this property, eventually decreasing the thermal conductivity of the composite (e.g. for $0.10 \%$ of CNT-3500). Furthermore, thermal conductivity experimental values were compared with theoretical values obtained by the Lewis-Nielsen model. Good agreement between the theoretical and measured values was observed for the incorporation of CNT-35 and CNT-250 in 0.05\% (differences of up to 2.7\%); however, as the CNTs aspect ratio and content increased, the experimental results deviated from those predicted.

These findings indicate the good potential of CNTs to improve the thermal conductivity of cement-based materials while keeping their fresh and mechanical performance. The incorporation of CNTs with an intermediate aspect ratio (i.e. 250$)$ led to a $15 \%$ increase in the thermal conductivity of the composite for a relatively low CNTs content $(0.05 \%$ over the cement weight). Finally, the good dispersion of the CNTs would be a key factor to reach better performance.

\section{ACKNOWLEDGEMENTS}

The authors gratefully acknowledge the Brazilian research agencies National Council for Scientific and Technological Development (CNPq) and Santa Catarina Research Foundation (FAPESC) for providing the financial support for this research, and the Coordination for the Improvement of Higher Education Personnel (CAPES) for providing scholarships for the first, third and fifth authors.

\section{REFERENCES}

[1] F. Sanchez and K. Sobolev, "Nanotechnology in concrete: a review," Constr. Build. Mater., vol. 24, no. 11, pp. 2060-2071, 2010, http://dx.doi.org/10.1016/j.conbuildmat.2010.03.014.

[2] A. P. Svintsov, E. L. Shchesnyak, V. V. Galishnikova, R. S. Fediuk, and N. A. Stashevskaya, "Effect of nano-modified additives on properties of concrete mixtures during winter season," Constr. Build. Mater., vol. 237, pp. 117527, 2020, http://dx.doi.org/10.1016/j.conbuildmat.2019.117527.

[3] S. Kawashima, P. Hou, D. J. Corr, and S. P. Shah, "Modification of cement-based materials with nanoparticles," Cement Concr. Compos., vol. 36, no. 1, pp. 8-15, 2013, http://dx.doi.org/10.1016/j.cemconcomp.2012.06.012. 
[4] T. C. de Souza, G. Pinto, V. S. Cruz, M. Moura, L. O. Ladeira, and J. M. Calixto, "Evaluation of the rheological behavior, hydration process, and mechanical strength of Portland cement pastes produced with carbon nanotubes synthesized directly on clinker," Constr. Build. Mater., vol. 248, pp. 118686, 2020, http://dx.doi.org/10.1016/j.conbuildmat.2020.118686.

[5] L. Silvestro and P. Jean Paul Gleize, "Effect of carbon nanotubes on compressive, flexural and tensile strengths of Portland cementbased materials: a systematic literature review," Constr. Build. Mater., vol. 264, pp. 120237, Dec 2020, http://dx.doi.org/10.1016/j.conbuildmat.2020.120237.

[6] Y. Hu, D. Luo, P. Li, Q. Li, and G. Sun, "Fracture toughness enhancement of cement paste with multi-walled carbon nanotubes," Constr. Build. Mater., vol. 70, pp. 332-338, 2014, http://dx.doi.org/10.1016/j.conbuildmat.2014.07.077.

[7] R. Hamzaoui, S. Guessasma, B. Mecheri, A. M. Eshtiaghi, and A. Bennabi, "Microstructure and mechanical performance of modified mortar using hemp fibres and carbon nanotubes," Mater. Des., vol. 56, pp. 60-68, 2014, http://dx.doi.org/10.1016/j.matdes.2013.10.084.

[8] S. Parveen, S. Rana, R. Fangueiro, and M. C. Paiva, "Microstructure and mechanical properties of carbon nanotube reinforced cementitious composites developed using a novel dispersion technique," Cement Concr. Res., vol. 73, pp. 215-227, 2015, http://dx.doi.org/10.1016/j.cemconres.2015.03.006.

[9] C. Zhou, F. Li, J. Hu, M. Ren, J. Wei, and Q. Yu, "Enhanced mechanical properties of cement paste by hybrid graphene oxide/carbon nanotubes," Constr. Build. Mater., vol. 134, pp. 336-345, 2017, http://dx.doi.org/10.1016/j.conbuildmat.2016.12.147.

[10] M. Jung, Y. Lee, S.-G. Hong, and J. Moon, "Carbon nanotubes (CNTs) in ultra-high performance concrete (UHPC): Dispersion, mechanical properties, and electromagnetic interference (EMI) shielding effectiveness (SE)," Cement Concr. Res., vol. 131, pp. 106017, 2020, http://dx.doi.org/10.1016/j.cemconres.2020.106017.

[11] X. Song, S. Shang, D. Chen, and X. Gu, "Multi-walled carbon nanotube reinforced mortar-aggregate interfacial properties," Constr. Build. Mater., vol. 133, pp. 57-64, 2017, http://dx.doi.org/10.1016/j.conbuildmat.2016.12.034.

[12] B. S. Sindu and S. Sasmal, "Properties of carbon nanotube reinforced cement composite synthesized using different types of surfactants," Constr. Build. Mater., vol. 155, pp. 389-399, 2017, http://dx.doi.org/10.1016/j.conbuildmat.2017.08.059.

[13] B. Zou, S. J. Chen, A. H. Korayem, F. Collins, C. M. Wang, and W. H. Duan, "Effect of ultrasonication energy on engineering properties of carbon nanotube reinforced cement pastes," Carbon N. Y., vol. 85, pp. 212-220, 2015, http://dx.doi.org/10.1016/j.carbon.2014.12.094.

[14] S. Xu, J. Liu, and Q. Li, "Mechanical properties and microstructure of multi-walled carbon nanotube-reinforced cement paste," Constr. Build. Mater., vol. 76, pp. 16-23, 2015, http://dx.doi.org/10.1016/j.conbuildmat.2014.11.049.

[15] M. S. Konsta-Gdoutos, Z. S. Metaxa, and S. P. Shah, "Highly dispersed carbon nanotube reinforced cement based materials," Cement Concr. Res., vol. 40, no. 7, pp. 1052-1059, 2010, http://dx.doi.org/10.1016/j.cemconres.2010.02.015.

[16] B. Rodriguez, E. Correa, Y. P. Arias, J. H. Quintero, J. A. Calderón, and O. A. Mendoza, "Carbonation study in a cement matrix with carbon nanotubes," J. Phys. Conf. Ser., vol. 1247, no. 1, pp. 012024, 2019, http://dx.doi.org/10.1088/1742-6596/1247/1/012024.

[17] V. Potapov, R. Fediuk, and D. Gorev, "Obtaining sols, gels and mesoporous nanopowders of hydrothermal nanosilica," J. Sol-Gel Sci. Technol., vol. 94, no. 3, pp. 681-694, 2020., http://dx.doi.org/10.1007/s10971-020-05216-z.

[18] A. Cwirzen, K. Habermehl-Cwirzen, and V. Penttala, "Surface decoration of carbon nanotubes and mechanical properties of cement/carbon nanotube composites," Adv. Cement Res., vol. 20, no. 2, pp. 65-73, 2008, http://dx.doi.org/10.1680/adcr.2008.20.2.65.

[19] H. Xie, A. Cai, and X. Wang, "“Thermal diffusivity and conductivity of multiwalled carbon nanotube arrays," Phys. Lett. Sect. A Gen," Solid State Phys., vol. 369, no. 1-2, pp. 120-123, 2007, http://dx.doi.org/10.1016/j.physleta.2007.02.079.

[20] J. Makar, J. Margeson and J. Luh, Carbon Nanotube/Cement Composites: Early Results and Potential Applications. Ottawa: NRC, 2005.

[21] D. D. L. Chung, "Cement-matrix structural nanocomposites," Met. Mater. Int., vol. 10, no. 1, pp. 55-67, 2004., http://dx.doi.org/10.1007/BF03027364.

[22] P. R. de Matos, R. Junckes, E. Graeff, and L. R. Prudêncio Jr, "Effectiveness of fly ash in reducing the hydration heat release of mass concrete," J. Build. Eng., vol. 28, pp. 101063, 2019. http://dx.doi.org/10.1016/j.jobe.2019.101063.

[23] M. J. Biercuk, M. C. Llaguno, M. Radosavljevic, J. K. Hyun, A. T. Johnson, and J. E. Fischer, "Carbon nanotube composites for thermal management," Appl. Phys. Lett., vol. 80, no. 15, pp. 2767-2769, 2002, http://dx.doi.org/10.1063/1.1469696.

[24] L. E. Evseeva and S. A. Tanaeva, "Thermal conductivity of micro-and nanostructural epoxy composites at low temperatures," Mech. Compos. Mater., vol. 44, no. 1, pp. 87-92, 2008, http://dx.doi.org/10.1007/s11029-008-0010-1.

[25] P. C. Ma, B. Z. Tang, and J. K. Kim, "Effect of CNT decoration with silver nanoparticles on electrical conductivity of CNT-polymer composites," Carbon N. Y., vol. 46, no. 11, pp. 1497-1505, 2008, http://dx.doi.org/10.1016/j.carbon.2008.06.048.

[26] D. Cai and M. Song, "Latex technology as a simple route to improve the thermal conductivity of a carbon nanotube/polymer composite," Carbon N. Y., vol. 46, no. 15, pp. 2107-2112, 2008, http://dx.doi.org/10.1016/j.carbon.2008.09.001.

[27] G. Skripkiunas, E. Karpova, J. Bendoraitiene, and I. Barauskas, "Effect of MWCNT and PCE plasticizer on the properties of cement pastes," IOP Conf. Ser. Mater. Sci. Eng., vol. 660, no. 1, 012032, 2019, http://dx.doi.org/10.1088/1757-899X/660/1/012032. 
[28] G. Skripkiunas, E. Karpova, I. Barauskas, J. Bendoraitiene, and G. Yakovlev, "Rheological properties of cement pastes with multiwalled carbon nanotubes," Adv. Mater. Sci. Eng., vol. 2018, pp. 1-13, 2018, http://dx.doi.org/10.1155/2018/8963542.

[29] F. Collins, J. Lambert, and W. H. Duan, "The influences of admixtures on the dispersion, workability, and strength of carbon nanotube-OPC paste mixtures," Cement Concr. Compos., vol. 34, no. 2, pp. 201-207, 2012, http://dx.doi.org/10.1016/j.cemconcomp.2011.09.013.

[30] M. S. Konsta-Gdoutos, Z. S. Metaxa, and S. P. Shah, "Multi-scale mechanical and fracture characteristics and early-age strain capacity of high performance carbon nanotube/cement nanocomposites," Cement Concr. Compos., vol. 32, no. 2, pp. 110-115, 2010, http://dx.doi.org/10.1016/j.cemconcomp.2009.10.007.

[31] R. K. Abu Al-Rub, A. I. Ashour, and B. M. Tyson, "On the aspect ratio effect of multi-walled carbon nanotube reinforcements on the mechanical properties of cementitious nanocomposites," Constr. Build. Mater., vol. 35, pp. 647-655, 2012, http://dx.doi.org/10.1016/j.conbuildmat.2012.04.086.

[32] Associação Brasileira de Normas Técnicas, Cimento Portland-Requisitos, NBR 16697, 2018.

[33] J. Engmann, C. Servais, and A. S. Burbidge, "Squeeze flow theory and applications to rheometry: a review," J. Nonnewton. Fluid Mech., vol. 132, no. 1-3, pp. 1-27, 2005, http://dx.doi.org/10.1016/j.jnnfm.2005.08.007.

[34] G. H. Meeten, "Yield stress of structured fluids measured by squeeze flow," Rheol. Acta, vol. 39, no. 4, pp. 399-408, 2000, http://dx.doi.org/10.1007/s003970000071.

[35] B. H. Min, L. Erwin, and H. M. Jennings, "Rheological behaviour of fresh cement paste as measured by squeeze flow," J. Mater. Sci., vol. 29, no. 5, pp. 1374-1381, 1994, http://dx.doi.org/10.1007/BF00975091.

[36] T. H. Phan and M. Chaouche, "Rheology and stability of self-compacting concrete cement pastes," Appl. Rheol., vol. 15, no. 5, pp. 336-343, Oct 2005, http://dx.doi.org/10.1515/arh-2005-0017.

[37] F. A. Cardoso, V. M. John, R. G. Pileggi, and P. F. G. Banfill, "Characterisation of rendering mortars by squeeze-flow and rotational rheometry," Cement Concr. Res., vol. 57, pp. 79-87, 2014, http://dx.doi.org/10.1016/j.cemconres.2013.12.009.

[38] F. A. Cardoso, V. M. John, and R. G. Pileggi, "Rheological behavior of mortars under different squeezing rates," Cement Concr. Res., vol. 39, no. 9, pp. 748-753, 2009, http://dx.doi.org/10.1016/j.cemconres.2009.05.014.

[39] A. R. G. Azevedo, J. Alexandre, E. B. Zanelato, and M. T. Marvila, "Influence of incorporation of glass waste on the rheological properties of adhesive mortar," Constr. Build. Mater., vol. 148, pp. 359-368, 2017, http://dx.doi.org/10.1016/j.conbuildmat.2017.04.208.

[40] P. R. Matos, R. Pilar, C. A. Casagrande, P. J. P. Gleize, and F. Pelisser, "Comparison between methods for determining the yield stress of cement pastes," J. Braz. Soc. Mech. Sci. Eng., vol. 42, no. 1, pp. 24, 2020, http://dx.doi.org/10.1007/s40430-019-2111-2.

[41] F. A. Cardoso et al., "Experimental developments of the squeeze flow test for mortars," in Proc. Int. Conf. Rheol. Process. Constr. Mater., 2020, pp. 182-190.

[42] T. Log and S. E. Gustafsson, "Transient plane source (TPS) technique for measuring thermal transport properties of building materials," Fire Mater., vol. 19, no. 1, pp. 43-49, 1995, http://dx.doi.org/10.1002/fam.810190107.

[43] N. Roussel, G. Ovarlez, S. Garrault, and C. Brumaud, "The origins of thixotropy of fresh cement pastes," Cement Concr. Res., vol. 42, no. 1, pp. 148-157, 2012, http://dx.doi.org/10.1016/j.cemconres.2011.09.004.

[44] S. C. Paul, A. S. van Rooyen, G. P. A. G. van Zijl, and L. F. Petrik, "Properties of cement-based composites using nanoparticles: A comprehensive review," Constr. Build. Mater., vol. 189, pp. 1019-1034, 2018., http://dx.doi.org/10.1016/j.conbuildmat.2018.09.062.

[45] L. Vaisman, H. D. Wagner, and G. Marom, "The role of surfactants in dispersion of carbon nanotubes," Adv. Colloid Interface Sci., vol. 128-130, pp. 37-46, 2006, http://dx.doi.org/10.1016/j.cis.2006.11.007.

[46] S. Ma, Y. Qian, and S. Kawashima, "Performance-based study on the rheological and hardened properties of blended cement mortars incorporating palygorskite clays and carbon nanotubes," Constr. Build. Mater., vol. 171, pp. 663-671, 2018, http://dx.doi.org/10.1016/j.conbuildmat.2018.03.121.

[47] N. Mohamadian, M. Z. Ramhormozi, D. A. Wood, and R. Ashena, "Reinforcement of oil and gas wellbore cements with a methyl methacrylate/carbon-nanotube polymer nanocomposite additive," Cement Concr. Compos., vol. 114, pp. 103763, 2020, http://dx.doi.org/10.1016/j.cemconcomp.2020.103763.

[48] A. Yahia, "Effect of solid concentration and shear rate on shear-thickening response of high-performance cement suspensions," Constr. Build. Mater., vol. 53, pp. 517-521, 2014, http://dx.doi.org/10.1016/j.conbuildmat.2013.10.078.

[49] J. Hot, H. Bessaies-Bey, C. Brumaud, M. Duc, C. Castella, and N. Roussel, "Adsorbing polymers and viscosity of cement pastes," Cement Concr. Res., vol. 63, pp. 12-19, 2014., http://dx.doi.org/10.1016/j.cemconres.2014.04.005.

[50] M. Tafesse and H. K. Kim, "The role of carbon nanotube on hydration kinetics and shrinkage of cement composite," Compos., Part B Eng., vol. 169, pp. 55-64, 2019, http://dx.doi.org/10.1016/j.compositesb.2019.04.004.

[51] R. K. Abu Al-Rub, A. I. Ashour, and B. M. Tyson, "On the aspect ratio effect of multi-walled carbon nanotube reinforcements on the mechanical properties of cementitious nanocomposites," Constr. Build. Mater., vol. 35, pp. 647-655, 2012, http://dx.doi.org/10.1016/j.conbuildmat.2012.04.086. 
[52] P. R. Matos, R. Pilar, C. A. Casagrande, P. J. P. Gleize, and F. Pelisser, "Comparison between methods for determining the yield stress of cement pastes," J. Braz. Soc. Mech. Sci. Eng., vol. 42, no. 1, pp. 24, Jan 2020, http://dx.doi.org/10.1007/s40430-019-2111-2.

[53] A. J. N. MacLeod, A. Fehervari, W. P. Gates, E. O. Garcez, L. P. Aldridge, and F. Collins, "Enhancing fresh properties and strength of concrete with a pre-dispersed carbon nanotube liquid admixture," Constr. Build. Mater., vol. 247, pp. 118524, 2020, http://dx.doi.org/10.1016/j.conbuildmat.2020.118524.

[54] M. O. Mohsen, R. Taha, A. Abu Taqa, and A. Shaat, "Optimum carbon nanotubes' content for improving flexural and compressive strength of cement paste," Constr. Build. Mater., vol. 150, pp. 395-403, 2017, http://dx.doi.org/10.1016/j.conbuildmat.2017.06.020.

[55] O. A. Mendoza Reales, Y. P. Arias Jaramillo, J. C. Ochoa Botero, C. A. Delgado, J. H. Quintero, and R. D. Toledo Fo., "Influence of MWCNT/surfactant dispersions on the rheology of Portland cement pastes," Cement Concr. Res., vol. 107, pp. 101-109, 2018, http://dx.doi.org/10.1016/j.cemconres.2018.02.020.

[56] B. M. Tyson, R. K. Abu Al-Rub, A. Yazdanbakhsh, and Z. Grasley, "Carbon nanotubes and carbon nanofibers for enhancing the mechanical properties of nanocomposite cementitious materials," J. Mater. Civ. Eng., vol. 23, no. 7, pp. 1028-1035, 2011, http://dx.doi.org/10.1061/(ASCE)MT.1943-5533.0000266.

[57] C. A. Casagrande, L. F. Jochem, L. Onghero, P. Ricardo de Matos, W. L. Repette, and P. J. P. Gleize, "Effect of partial substitution of superplasticizer by silanes in Portland cement pastes," J. Build. Eng., vol. 29, pp. 2019, 2020, http://dx.doi.org/10.1016/j.jobe.2020.101226.

[58] A. Sobolkina et al., "Dispersion of carbon nanotubes and its influence on the mechanical properties of the cement matrix," Cement Concr. Compos., vol. 34, no. 10, pp. 1104-1113, 2012, http://dx.doi.org/10.1016/j.cemconcomp.2012.07.008.

[59] K. Pietrak and T. Wiśniewski, "A review of models for effective thermal conductivity of composite materials," J. Power Technol., vol. 95, no. 1, pp. 14-24, 2015.

[60] Y. Xu, G. Ray, and B. Abdel-Magid, "Thermal behavior of single-walled carbon nanotube polymer-matrix composites," Compos., Part A Appl. Sci. Manuf., vol. 37, no. 1, pp. 114-121, 2006., http://dx.doi.org/10.1016/j.compositesa.2005.04.009.

[61] A. Bejan and A. D. Kraus, Heat Transfer Handbook, 1st ed. New Jersey: Wiley-Interscience, 2003.

Author contributions: EB: methodology, data curation, formal analysis, writing; PJPG: conceptualization, funding acquisition, supervision; PM: methodology; data curation; FP: data curation; formal analysis; PRM: writing, review and edition.

Editors: José Marcio Calixto, Guilherme Aris Parsekian. 